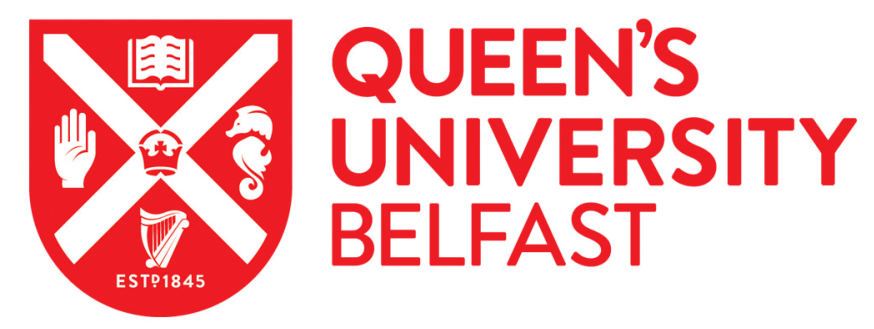

\title{
Increasing the Wireless Power Transfer (WPT) Link Efficiency by High Gain Helices
}

Mardani, H., Buchanan, N., Fusco, V., \& Naeem, U. (2021). Increasing the Wireless Power Transfer (WPT) Link Efficiency by High Gain Helices. In 2021 IEEE Texas Symposium on Wireless and Microwave Circuits and Systems (WMCS): Proceedings Institute of Electrical and Electronics Engineers Inc.. https://doi.org/10.1109/WMCS52222.2021.9493291

Published in:

2021 IEEE Texas Symposium on Wireless and Microwave Circuits and Systems (WMCS): Proceedings

\section{Document Version:}

Peer reviewed version

\section{Queen's University Belfast - Research Portal:}

Link to publication record in Queen's University Belfast Research Portal

\section{Publisher rights}

Copyright 2021 IEEE. This work is made available online in accordance with the publisher's policies. Please refer to any applicable terms of use of the publisher.

\section{General rights}

Copyright for the publications made accessible via the Queen's University Belfast Research Portal is retained by the author(s) and / or other copyright owners and it is a condition of accessing these publications that users recognise and abide by the legal requirements associated with these rights.

Take down policy

The Research Portal is Queen's institutional repository that provides access to Queen's research output. Every effort has been made to ensure that content in the Research Portal does not infringe any person's rights, or applicable UK laws. If you discover content in the Research Portal that you believe breaches copyright or violates any law, please contact openaccess@qub.ac.uk. 


\title{
Increasing the Wireless Power Transfer (WPT) Link Efficiency by High Gain Helices
}

\author{
Hossein Mardani ${ }^{\# 1}$, Neil Buchanan ${ }^{\# 2}$, Vincent Fusco ${ }^{\# 3}$, Umair Naeeim ${ }^{\# 4}$ \\ ${ }^{*}$ CWI, ECIT, Queen's University of Belfast, UK \\ $\left\{{ }^{1}\right.$ h.mardani, ${ }^{4}$ u.naeem $\} @ q u b . a c . u k,\left\{{ }^{2}\right.$ n.buchanan, ${ }^{3}$ v.fusco $\} @$ ecit.qub.ac.uk
}

\begin{abstract}
In this study we compare helix and patch array antenna characteristics for wireless power transfer (WPT). It will be shown that the helices offer higher link efficiency for a similar beam scanning limit compared to patch antenna elements. We provide 12-by-12 element planar array results for both cases at different element spacings. The frequency band of interest is ISM 2.4-2.5GHz and we do the comparisons in this range. It is concluded that helix elements, when used as an array, offer significant improvements for wireless power link efficiency, whilst also offering a reasonable beam scanning range.
\end{abstract}

Keywords - antennas, helix, patch, phased arrays, WPT, MPT.

\section{INTRODUCTION}

Transferring electrical power without connected wires or cables has been sought after, for a long time. Many studies have been done to analyze transferring power through radio waves. WPT is possible in different ways. For short ranges it is viable through Inductive, capacitive and magnetodynamic coupling. Resonant inductive coupling is used for the mid-range power transmission, and for long-range purposes microwave and light wave technologies are the preferable approaches. Our study is concentrated on microwave power transmission (MPT). A MPT system includes four integral parts as power amplifier, transmit antenna, receive antenna, and rectifying circuit, which together with the antenna element is called a Rectenna. The aim is to increase the power efficiency in each section to have an efficient MPT system. Transmitter and receiver antenna characteristics can highly affect the total system efficiency. Depending on the application, different types of antennas may be used. Phased array antennas with retrodirective approach has attracted much attention in recent years [1]. For sure, the aperture size, spacing between array elements and the type and gain of the elements are important factors which each play a role in affecting the link efficiency. Brown [2] in 1974 provided useful design curves for calculating the WPT link efficiency in the near and far field ranges. Shinohara et al [3] investigated the antenna beam shape effects on the received power. In [4] a focused microstrip antenna array was proposed to increase the link efficiency. A comprehensive study of array designs for long-distance wireless power transmission has been provided in [5].

To evaluate how the arrays composed of high gain elements might increase the efficiency of WPT link, we compare the realized gain of 144-element helix and patch arrays at different inter element spacings. The maximum scan angle capability of each array is identified by the limit at which the first appearing grating lobe magnitude is equal to the first side lobe level.

\section{HELIX AND PATCH DESIGNS}

Helix and patch elements are shown in Fig. 1. Fig. 1(a) depicts the helix structure and its dimensions. It has 7 turns with the vertical dimension of $19 \mathrm{~cm}$ and aperture diameter of $4.6 \mathrm{~cm}$. This helix is operating in axial mode, and radiates a right hand circular polarized (RHCP) wave. In Fig. 2(b) we can see the probe-fed patch element. This patch antenna was designed on a RT-Duriod 5880 substrate with thickness of $0.254 \mathrm{~mm}$. The return loss of helix and patch antennas is depicted in Fig. 2.

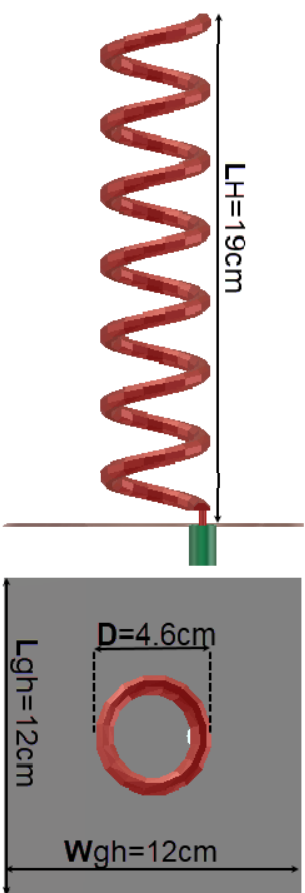

(a)
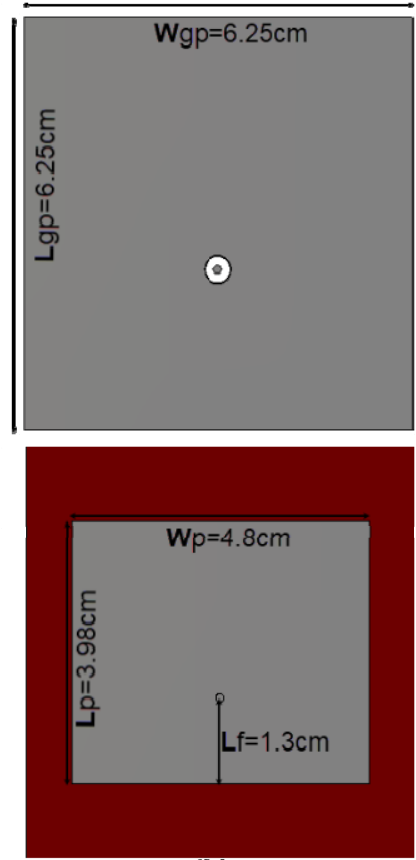

(b)
Fig. 1. Helix (a) and patch antenna (b) dimensions.

The impedance bandwidth of helix antenna quite large, but this is not very significant for MPT, as we are only interested in radiating at a single frequency in the frequency range of 2.4$2.5 \mathrm{GHz}$. The curve shows the helix S11 is lower than $-10 \mathrm{~dB}$ in the desired frequency band. From Fig. 2. We see that the designed patch antenna has a resonance at $2.47 \mathrm{GHz}$ with an impedance bandwidth of around $30 \mathrm{MHz}$. 


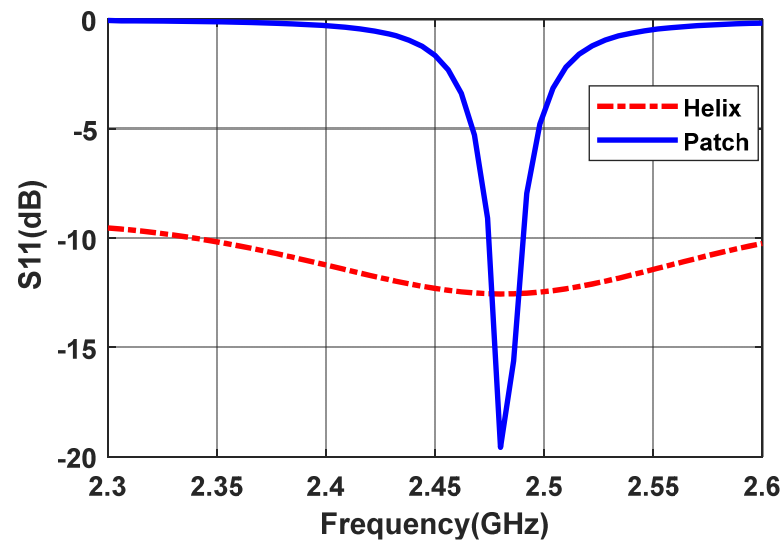

Fig. 2. The S11 of patch and helix antennas.

\section{HELIX AND PATCH RADIATION PATTERNS}

In this section, we draw a comparison between the radiation patterns of helix and patch elements. In Fig. 3. The radiation patterns of helix and patch elements are shown in one plane. As we are mostly interested in gain comparison, the pattern in another plane has not been included. It is seen that the helix element has $12.4 \mathrm{dBi}$ realized gain at $2.47 \mathrm{GHz}$ while the patch element produces a realized gain of $6.8 \mathrm{dBi}$ at this frequency.

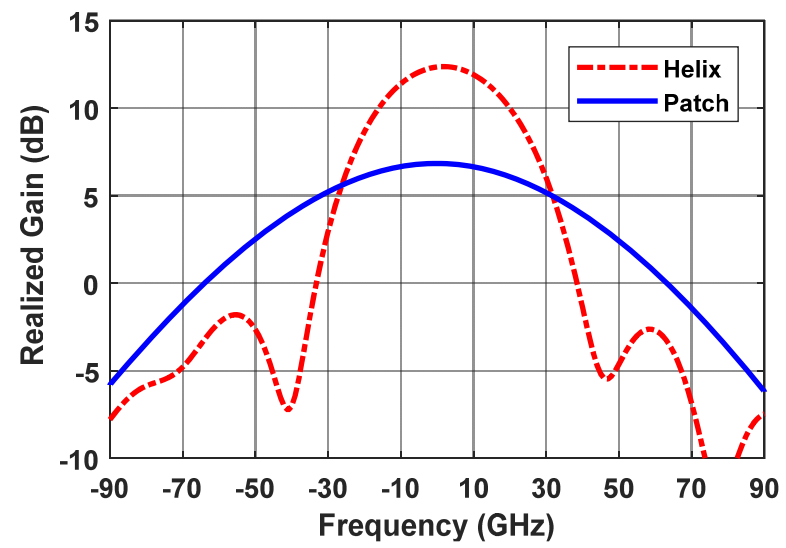

Fig. 3. Radiation patterns of helix and patch antennas.

We know that the helix element here, is a traveling wave antenna with its gain dependent on the number of turns, or in other words on its length. The gain of the designed helix is $5.6 \mathrm{~dB}$ higher than the patch element and this is enough for us to do the comparison between arrays composed of these elements in terms of WPT link efficiency. We notice from Fig. 3. that the half power beam width (HPBW) of helix and patch elements is around 30 and 90 degrees respectively. We know that the scanning ability of a phased array antenna, is dependent on the spacing between its elements which dictates appearance of grating lobes. In next section, we do a comparison about gain and scanning capabilities of the mentioned antennas.
At first, we compare the element-to-element links of patch and helix antennas. This comparison is done at the same distances $(\mathrm{d}=100 \mathrm{~cm})$ between TX and RX antennas with transmit power of $0.5 \mathrm{~W}$ for both cases. Fig. 4. Illustrates the patch and helix links. The Transmit and receive antennas are same in each case. The receive antennas are both loaded with 50 ohm resistors. We are interested to compare the received power by these loads. Fig. 5 depicts the received power at the terminal of helix and patch vs frequency. The simulation was done by CST [6] software. It is apparent that in the helix and patch links, the received power at $2.47 \mathrm{GHz}$ is $0.0104 \mathrm{w}$ and $0.008 \mathrm{w}$ respectively. It means in the helix link case, the received power is 13 times more than the patch link. This is very close to the value calculated by the Friis formula, which is 13.2. In the following section, we compare array antenna characteristics of these elements.

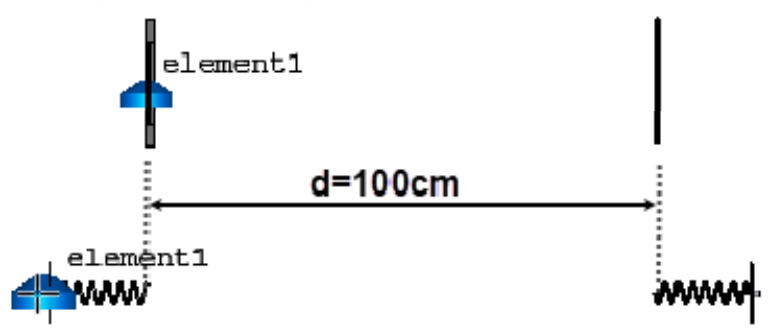

Fig. 4. Helix and patch links in CST.

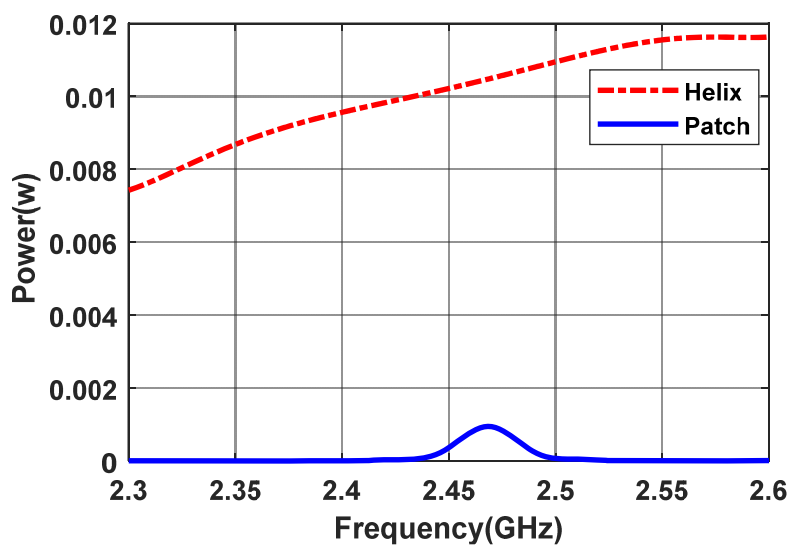

Fig. 5. Power received by patch and helix elements.

A double helix link budget test was done in the QUB's anechoic antenna chamber at the RX to TX distance of $\mathrm{d}=5.6 \mathrm{~m}$ and $\mathrm{f}=32.5 \mathrm{GHz}$. Using a power meter the power level of $-3.73 \mathrm{dBm}$ was measured at the connector feeding the transmit antenna. Then, we used the power meter to measure the received power by the second helix antenna. The value read was $-34.4 \mathrm{dBm}$ which is very close to the $-34.1 \mathrm{dBm}$ calculated by Friis formula for antennas with $12.5 \mathrm{dBi}$ gain. The picture of link test in anechoic chamber is shown in Fig. 6.

\section{TEST RESULTS}




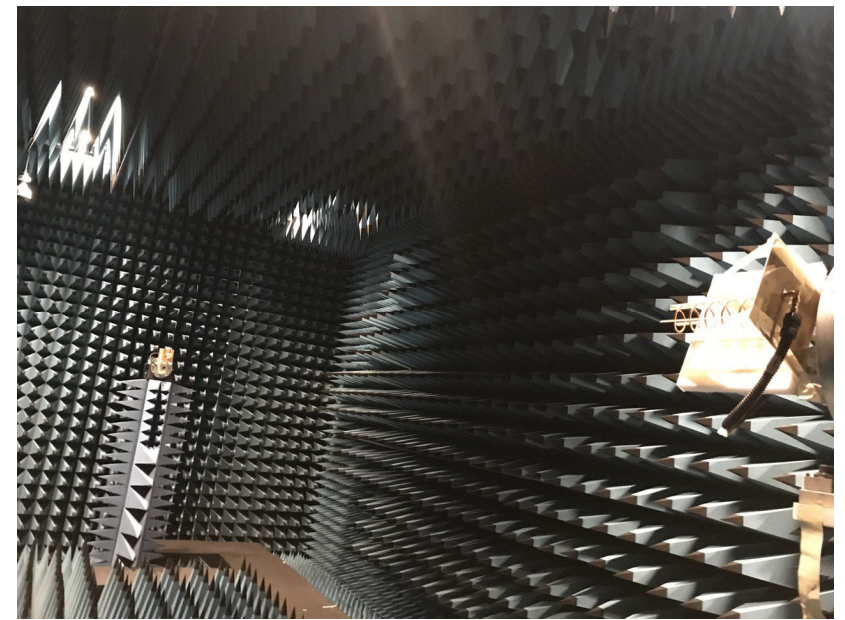

Fig. 6. Double helix antennas under test for received power.

\section{HELIX AND PATCH ARRAYS, CHARACTERISTICS}

In section IV, a comparison was done between helix-to-helix and patch-to-patch scenarios in terms of link efficiency. We noticed that the helix link provides 13 times better power delivery. However, when these elements are populated in an array form, they will show different characteristics rather than when isolated. This is because of the gain difference between these elements. We can divide high gain elements in 2 categories, one with large and the other with small physical aperture. In fact, in the large aperture high gain elements, the gain is directly dependent on the physical aperture size while in small aperture elements like helices or dielectric rod antennas the gain is dependent on the length, not the physical aperture. It means for smaller aperture high gain elements, it is possible to have arrays with shorter inter element spacing. Although, we should bear in mind that the array characteristics depend on the electrical aperture size too. In other words, as long as the electrical aperture of neighboring elements overlap, the array gain will not reach its maximum. The antenna electrical aperture size and directivity are dependent on each other by the following formula:

$$
A_{e}=\frac{\lambda^{2}}{4 \pi} D
$$

Where $A_{e}$ is the electrical aperture area, $D$ is the directivity of array antenna and $\lambda$ is wavelength. This formula shows a linear relationship between antenna directivity and electrical aperture. In fact, the larger the directivity, the larger the electrical aperture would be. Therefore, for an array of high gain elements, the inter element spacing must be large enough so the array can deliver its maximum potential gain. But, this causes the problem of grating lobes for scanned arrays. Here we intend to compare patch and helix arrays in terms of array gains and beam steering capabilities. We set the criterion for maximum scan to an angle where the grating lobes' magnitudes are lower than the first side lobes levels (SLL). As we do not consider any amplitude taper, the first SLL would be $13.5 \mathrm{~dB}$ lower that the main beam.

\section{GAIN AND SCAN ANGLE LIMIT COMPARISON}

To compare helix (as high gain element) and patch (as low gain element) arrays, we consider a 144-element (12-by-12) planar array with different element spacings. Table. 1 includes the data about this comparison. This table shows the information about the helix array gain (HAG), helix array scan limit (HASL), patch array gain (PAG) and patch array scan limit (PASL) capabilities over different element spacings. It is apparent that in the patch array case, for spacings beyond $12 \mathrm{~cm}$, the grating lobe magnitude is higher than the side lobe level even in zero scan conditions. As we know for spacings higher than $\lambda$ the grating lobes will appear even in zero scan or broadside radiation situation. We will assume, for a WPT transmit array, that a 20 degrees scan limit is acceptable. From this assumption, Table 1 shows that the 144 element patch array has a gain of $30.4 \mathrm{dBi}$, whereas the helix array delivers $32.5 \mathrm{dBi}$ realized gain. This $2.1 \mathrm{~dB}$ increase in gain for the helix array equates to a $62 \%$ better link efficiency contribution for the helix array on the transmit side. This shows that the helix array would offer a very significant improvement in MPT links, requiring beam scanning capability. The better scan capabilities of the helix array compared to the patch array, is due to the narrower beamwidth patterns of the helix elements. As the grating lobe magnitude is multiplied by the high gain element pattern, the overall radiation pattern of the array produces lower grating lobe levels compared to the low gain element case which has a flatter gain value over its radiation angle.

Table.1. 144-element helix and patch arrays results.

\begin{tabular}{|l|l|l|l|l|}
\hline Spacing(cm) & HAG(dBi) & HASL(deg) & PAG(dBi) & PASL(deg) \\
\hline 7 & 28.1 & 90 & 27.5 & 80 \\
\hline 8 & 29.2 & 60 & 28.6 & 50 \\
\hline 9 & 30.2 & 46 & 29.6 & 34 \\
\hline 10 & 31.1 & 30 & 30.4 & 20 \\
\hline 11 & 32 & 27 & 31 & 8 \\
\hline 12 & 31.6 & 25 & 28 & 0 \\
\hline 13 & 31.8 & 22 & 27.9 & 0 \\
\hline 14 & 32.5 & 20 & 28.5 & 0 \\
\hline 15 & 33.4 & 18 & 28.8 & 0 \\
\hline 16 & 34.1 & 14 & 29 & 0 \\
\hline
\end{tabular}

\section{CONCLUSION}

A comparison has been carried out between high gain helix and patch phased array antennas, in terms of gain and scan limits. The study showed that the array antenna composed of high gain helices, delivers higher gain within the same scan limits comparing to a patch array with a similar aperture area. This means, helix elements are suitable candidates for highefficiency moving-object MPT. 


\section{References}

[1] V. Fusco, N. Buchanan, "Developments in retrodirective array technology", IET Microw. Antennas Propagat., vol. 7, no. 2, pp. 131-140, 2013.

[2] W. C. Brown, "The technology and application of free-space power transmission by microwave beam", Proc. IEEE, vol. 62, no. 1, pp. 11-25, 1974.

[3] Shinohara, N., "Beam Efficiency of Wireless Power Transmission via Radio Waves from Short Range to Long Range", Journal of the Korean Institute of Electromagnetic Engineering and Science, Vol.10, No.4, pp.224-230, 2011.

[4] L. Shan, W. Geyi, "Optimal design of focused antenna arrays", IEEE Trans. Antennas Propag., vol. 62, no. 11, pp. 5565-5571, Nov. 2014.

[5] G. Massa, F. Oliveri, P.R. Viani, "Array designs for long-distance wireless power transmission: state-of-the-art and innovative solutions", Proc. IEEE, vol. 101, no. 6, pp. 1464-1481, 2013.

[6] CST Microwave Studio, version 2018. 